Methods The aim of this research is to assess the situation in our health care settings before and after the actions undertaken in 2011. The research was performed from data collected by the Shocroom (strategic health operations centre), freely provided by the public health facilities. We collected 521 cases between 2011 and October 2015.

Results 521 incidents of verbal and/or physical violence against health workers were reported between 2011 and October 2015. The monthly average of incidents between 2011 and 2015 is as follows:

- 8.16 is the mean of incidents of violence against health workers reported to the Shocroom in 2011.

- 14.08 is the mean of incidents of violence against health workers reported to the Shocroom in 2012.

- 11.08 is the mean of incidents of violence against health workers reported to the Shocroom in 2013

- 8 is the mean of incidents of violence against health workers reported to the Shocroom in 2014.

- 10.22 is the mean of incidents of violence against health workers reported to the Shocroom in 2015.

We notice that despite the actions taken by the Ministry of Health, the number of reported attacks is increasing.

The research also found that $80 \%$ of the incidents of violence against health workers reported are physical.

The percentage of physical violence also increased between 2011 and 2015; it is respectively 78\% in 2011 and 90\% in 2015.

The actor of the violence is a relative of a patient in $61 \%$ of cases and in 39\% the patient himself.

Workplace violence affects all health workers, both physicians and nurses, men and women, though some are more at risk than others. Emergency and ambulance staff are more affected by this violence.

$22 \%$ of the incidents reported were followed by a cessation of work. And even when the victims kept working, there were high levels of stress and in some situations assistance from police.

Conclusions Violence towards health workers is a serious problem sometimes hindering the regular activity of health facilities by work interruptions it generates. In most cases, the actors are relatives of patients, which bring us to review the security measures in health settings.

The analysis of our data shows an increase of this flail in 2015, should we review our policies? Should we further strengthen our action plan in collaboration with other stakeholders such as the Ministry of Interior?

\section{DOMESTIC VIOLENCE AGAINST WOMEN IN RUSSIA AND ITS CONSEQUENCES}

Margarita Kachaeva, Ludmila Satianova. Serbsky National Research Centre for Psychiatry and Narcology, Moscow, Russia

\subsection{6/injuryprev-2016-042156.573}

Background Violence against women is a troubling phenomenon in Russia and also one with great social consequences. Many Russian families are a scene of a silent drama - a drama that society, the courts and other institutions are only beginning to learn to confront. The main purpose of this research is to find out origins of crimes in women who are victims of domestic violence.

Methods Clinical, psychological, statistical.

Results Forensic psychiatrists found out that domestic abuse against women is often one of the main causes of crimes of violence in women. A cohort of 8 females was examined by forensic psychiatrists and psychologists. All women were victims of violence and had committed murders of their husbands or partners whose violence towards women escalated in severity. Domestic abuse resulted in so called battered women syndrome. Clinical assessment has revealed depression, anxiety, fear, post traumatic stress disorder, alcohol abuse. At the time of the crime all women revealed depressive states.

Conclusions A research has been carried out on the basis of forensic psychiatric assessment of those women who had a long history of violence by their husbands or partners. The study has revealed the cycle of violence and the risk of women who are victims of domestic violence to become a perpetrators.

\section{ENHANCING COOPERATION OF MEDICAL AND SOCIAL SERVICES TO IMPROVE AID TO VICTIMS OF VIOLENCE IN ZAMBIA}

${ }^{1}$ Robert Mtonga, ${ }^{2}$ Maria Valenti, ${ }^{2}$ Michael Schober, ${ }^{3}$ Maria Valenti, ${ }^{2}$ Stephanie Hametner. 'Zambian Health Workers for Social Responsibility, Lusaka, Zambia; ${ }^{2}$ International Physicians for the Prevention of Nuclear War-Austria (IPPNW Österreich), Linz, Austria; ${ }^{3}$ International Physicians for the Prevention of Nuclear War, Somerville, Massachusetts, USA

\subsection{6/injuryprev-2016-042156.574}

Background In Zambia, gender-based violence (GBV) is on the rise, with one in five women having experienced sexual violence, and domestic violence frequently reported. Zambia has been working to tackle this. At the 66th World Health Assembly Zambia was one of seven countries that introduced a resolution on violence against women and girls and has also introduced national policies on GBV.

Methods A prospective study that was premised on pilot phase that compared a period prior to an intervention with another period following an intervention to study challenges to addressing GBV in Zambia include effective implementation, limited financial and human resources, and lack of public awareness.

Health professionals from Zambia and Austria collaborated to design a research and education project to address these issues and improve care outcomes for victims of interpersonal violence (IPEV). It was designed to build on existing health and social services infrastructures, improve networking among medical and social services, and below-cost. The intervention included training for medical and social service personnel and distribution at key locations of information on services available to IPEV victims.

Results Capitalising on existing resources, linking local services, and developing a low-cost intervention kept costs down in resource poor Zambia, where the annual government per capita health expenditure is US\$32 or about $11 \%$ of the annual national budget. Sustainability was encouraged by engaging local partners. Results: victims of IPEV had improved understanding of available social services; improved networking among partner organisations; new descriptive data about victims, and; for medical participants, improved cross-cultural understanding.

Conclusions Low-cost interventions may improve care for victims of violence in resource-poor settings. Improved cooperation among social service and medical providers may benefit victims of IPEV and also agencies through strengthened relationships and information flow. North-South cooperation should be encouraged at the institutional level. 